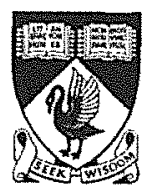

THE WORLD REAL INTEREST RATE:

STOCHASTIC INDEX NUMBER PERSPECTIVES

by

Ong Li Lian

H.Y. Izan

K. Clements

DISCUSSION PAPER 97.26

DEPARTMENT OF ECONOMICS

THE UNIVERSITY OF WESTERN AUSTRALIA NEDLANDS, WESTERN AUSTRALIA 6907

ISSN 0811-6067

ISBN 0-86422-824-4 
THE WORLD REAL INTEREST RATE: STOCHASTIC INDEX NUMBRE PERSPECTIVES*

\author{
by \\ Ong Li Lian \\ H.Y. Izan \\ Department of Accounting and Finance \\ The University of Western Australia \\ and \\ Kenneth W. Clements \\ Economic Research Centre \\ Department of Economics \\ The University of Western Australia
}

DISCUSSION PAPER 97.26

October, 1997

ISSN 0811-6067

ISBN 0-86422-824-4

*We would like to thank Joseph Gagnon for providing the data and for his helpful comments; and Robert Brooks, Richard Levich and Jason Mitchell for their helpful comments. 


\title{
THE WORLD REAL INTEREST RATE: STOCHASTIC INDEX NUMBER PERSPECTIVES
}

\begin{abstract}
In a recent paper, Gagnon and Unferth (1995) test the hypothesis of real interest rate equality by regressing real interest rates for all major countries on dummy variables for each country and each period. Interest rates in a given country are then said to exhibit departures from the world rate (and real interest rate equality is rejected) if the coefficient of the dummy variable for that country is significant. We show that this model can be interpreted as an application of the stochastic approach to index numbers. This approach leads to estimates of, and standard errors for, the real rate for the world as a whole, which have appealing indexnumber interpretations and foundations. Next, we extend Gagnon and Unferth's approach by weighting countries to recognise their differing importance in the world economy, in terms of relative GDP and trade. Weighting does not lead to appreciable changes in the results. Rather than using the CPI to define real rates, we also experiment with the WPI which gives more prominence to goods entering into international trade. The WPI results indicate that real rates are equalised internationally. However, when we define the "true" deflator as a weighted average of the CPI and the WPI, the results indicate that the CPI dominates.
\end{abstract}




\section{INTRODUCTION}

How do we determine if two regions share the same market? What about two countries which may or may not be neighbours? A useful way of thinking about this problem is to invoke some form of the "law of one price". This can be done according to which regions/countries are part of one market if the prices of relevant commodities/assets are more or less the same once appropriate adjustments have been made. Such adjustments would take into account differing currencies and, possibly, impediments to price equalisation which are approximately constant over time. Under this approach, the basic mechanism which equalises prices is one of arbitrage -- agents buy where the price is low and sell where high. A related mechanism which prevents prices within the same market from diverging is expectations. The expectation that pricing anomalies will soon be eliminated can itself rapidly bring about price equalisation without any physical movement of goods or assets. Application of these ideas in international finance include the celebrated (but controversial!) conditions of purchasing power parity, the link between exchange rates and prices, and the various forms of interest rate parity, the relationship between interest rates and exchange rates.

This paper deals with a particular version of interest rate parity, viz. the equalisation of real interest rates in different countries. Such equalisation has profound effects. If interest rates in real terms are the same internationally, then the cost of borrowing is independent of where that borrowing occurs and in what currency the loan is denominated. Moreover, the equalisation of real rates means that the role of monetary policy within any one country is very much circumscribed; in the limit, monetary policy can only affect domestic interest rates via its influences on the world interest rate. A world with highly mobile capital and integrated financial markets would seem to be not inconsistent with these implications of the equalisation of real interest rates.

We begin with a brief review of the basic interest rate parity conditions. 
The theory of covered interest rate parity (CIRP) is "a relationship between the premium (or discount) on a forward contract for foreign exchange and the differential in interest rates on securities that are identical in all respects except for the currency of denomination" (Frenkel and Levich, 1975, p. 337). This theory thus provides a link between domestic and foreign interest rates, and the spot and forward exchange rates. It is synonymous with covered arbitrage of nominal interest rates. When interest rates on comparable securities are used, tests give strong support to covered interest rate parity. 1

\section{(ii) Uncovered Interest Rate Parity}

The uncovered interest rate parity (UIRP) condition entails uncovered arbitrage of nominal interest rates so that the interest differential equals the expected change in the spot exchange rate. ${ }^{2}$ If the foreign exchange market is efficient, then the forward rate is an unbiased predictor of the future spot rate ("speculative efficiency", Bilson, 1981). Note that efficiency here means that participants in the foreign exchange market exhibit rational expectations and risk neutrality. CIRP plus speculative efficiency jointly imply UIRP. Uncovered interest parity is contentious and a large body of research has investigated whether or not investors demand a risk premium to compensate for an unhedged exposure to exchange-rate uncertainty. In general, as this research has yielded contradictory results, this issue is still unsettled. ${ }^{3}$

1 See also Dooley and Isard (1980), Frenkel and Levich (1977), Mussa and Goldstein (1993) and Popper (1990).

2 A related concept is real uncovered interest rate parity which links real interest differentials and real exchange rates. See Edison and Pauls (1993) for some recent evidence.

3 Cumby (1988), Fama (1984), Hansen and Hodrick (1983), Hodrick and Srivastava (1984) and Hsieh (1984) find support for the existence of such premia; however, Domowitz and Hakkio (1985) and Frankel (1982) find otherwise. Pope and Peel (1991) suggest that the foreign exchar.ge market is possibly inefficient, while Evans and Lewis (1995) show that systematic forecast errors can explain some of the deviations from uncovered interest rate parity, which also points in the direction of inefficiency. For surveys, see Frankel (1988) and Lewis (1995). 


\section{(iii) Real Interest Rate Equality}

The final parity condition relates to the equality of inflation-adjusted interest rates in different countries. Like UIRP, this is also an uncovered relationship between interest rates. As shown in Section II below, ex ante relative purchasing power parity and UIRP imply real interest rate equality (RIRE). In what follows, we provide a brief overview of previous research on RIRE.

Hodrick's (1979) bilateral tests on ex ante real interest rates in the US and other OECD countries indicate that the evidence is not inconsistent with the hypothesis of RIRE. Mishkin (1984), in turn, explores the multi-lateral performance of short-term real interest rates in the Euromarket for seven OECD countries. Unlike Hodrick, he is able to decisively reject the hypothesis of equality of real interest rates in these countries. The joint hypothesis of UIRP and ex ante relative PPP is also strongly rejected by Mishkin. Cumby and Obstfeld (1984) carry out tests of UIRP, ex ante relative PPP, as well as bilateral tests of ex ante RIRE between the US and five other OECD countries. With the exception of the US dollarDeutsche mark exchange rate, they also reject the hypothesis of UIRP. Furthermore, the expected exchange rate changes appear to be poor and biased predictors of relative inflation rates, thereby calling into question relative PPP. Cumby and Obstfeld also reject real interest rate equality in almost all cases.

Mark (1985) incorporates the effects of taxes into his analysis of RIRE but finds little support for the hypothesis of net-of-tax real rate equality. Similarly, Cumby and Mishkin (1986) find that although a significant positive correlation exists between real interest rate movements in the US and seven major industrialised countries, international linkages are less than complete. They also find no evidence that real rates are more closely linked within Europe than with the US. ${ }^{4}$

4 See Piggott (1993) and Mussa and Goldstein (1993) for further discussions on the convergence of real interest rates. 
Dutton (1993) argues that for the purposes of international comparisons, real interest rates should be defined in terms of traded goods prices alone; as non-traded goods are poorly arbitraged internationally, the prices of these goods should be excluded from the computation of real returns. Consequently, Dutton uses price indices constructed from the traded goods component of the CPI for the major OECD countries to deflate nominal interest rates; her results provide broad support for the equality hypothesis.

In a pioneering study, Gagnon and Unferth (1995) estimate the common component of real interest rates for all major countries, which they interpret as the world real interest rate. Their data consist of real interest rates of nine OECD countries over the 1977 to 1992 period. The authors argue that their study differs from previous ones in that they (i) focus on countries and time period with the most liberal domestic and international capital markets; (ii) allow for a constant risk premium across countries; and (iii) treat all countries symmetrically, whereas previous studies focus on bilateral parity relationships between the US and selected partner countries.

Our objective in this paper is to illustrate how stochastic index-number methodology (see, e.g., Selvanathan and Rao, 1994) can be used to measure the world real interest rate and test the hypothesis of RIRE. According to the stochastic approach to measuring inflation, each commodity price change is viewed as containing some information about the true (or underlying) rate of inflation, as well as some commodity-specific noise. This leads naturally to a signal-extraction problem of how to combine the noisy prices in such a way so as to yield an estimate of the rate of inflation which possesses some desirable statistical properties. In addition to a point estimate, this approach also leads to a standard error of inflation which, under certain conditions, increases when there is more variability in relative prices. This attractive result agrees with intuition that in times of large changes in relative prices, the meaning of the overall rate of inflation becomes more ambiguous. The availability of this standard error means that confidence intervals can be constructed for the underlying rate of inflation, and other inference procedures can be employed. It seems to us that this type of 
information would be highly valued by financial markets. It is for these reasons that advocates of the stochastic approach would like to see government agencies publish standard errors for inflation on a routine basis.

This paper is organised as follows. In Section $\Pi$, we demonstrate the conditions under which real interest rates are equalised internationally. Section III sets out stochastic indexnumber methodology. In Section IV, we show how Gagnon and Unferth's (1995) model can be reinterpreted in terms of the stochastic approach. Extensions of the basic idea to deal with differing country sizes, the distinction between traded and non-traded goods, the "true" real interest rate etc. are contained in Sections V and VI. The conclusion follows in Section VII.

\section{WHEN ARE REAL INTEREST RATES EQUALISED INTERNATIONALLY?}

In this section, we set out sufficient conditions for the equalisation of real interest rates internationally. We begin by defining the relative version of PPP, whereby the change in the exchange rate is equal to the inflation differential:

$$
\log \left(S_{t} / S_{t-1}\right)=\log \left(P_{t} / P_{t-1}\right)-\log \left(P_{t}^{*} / P_{t-1}^{*}\right)
$$

where $S$ is the spot exchange rate, and $P$ and $P^{*}$ are the price levels at home and abroad. Let this PPP relationship hold ex ante or in an expected sense.5 Thus if $E_{t}$ represents expectations conditional on information available at time $t$, then for any horizon of $k$ periods,

$$
E_{t}\left[\log \left(S_{t+k} / S_{t}\right)\right]=E_{t}\left[\log \left(P_{t+k} / P_{t}\right)-\log \left(P_{t+k}^{*} / P_{t}^{*}\right)\right]
$$

In words, the expected depreciation of the exchange rate reflects the expected inflation

5 In contrast to older results, recent evidence on PPP is fairly supportive, at least for longer-term horizons (Rogoff, 1996) and especially for hamburgers (Click, 1996, Cumby, 1996, Ong, 1997, Pakko and Pollard, 1996). 
differential.

Under UIRP, the nominal interest differential between similar $k$-period bonds denominated in different currencies $\left(R_{k t}-R_{k t}^{*}\right)$ must equal the expected change in the exchange rate over the holding period $k$ :

$$
R_{k t}-R_{k t}^{*}=E_{t}\left[\log \left(S_{t+k} / S_{t}\right)\right]
$$

where $R_{c, k, t}=\log \left(1+n_{c, k, t}\right)$ and $R_{k t}^{*}=\log \left(1+n_{k t}^{*}\right)$. The variables $n_{c, k, t}$ and $n_{k t}^{*}$ represent the $k$-period nominal interest rates for the domestic country $c$ and the foreign country at time $t$; respectively. Substituting (2) into (1), we obtain $R_{k t}-R_{k t}^{*}=E_{t}\left[\log \left(P_{t+k} / P_{t}\right)-\log \left(P_{t+k}^{*} / P_{t}^{*}\right)\right]$ which could also be rearranged as $R_{k t}-E_{t}\left[\log \left(P_{t+k} / P_{t}\right)\right]=R_{k t}^{*}-E_{t}\left[\log \left(P_{t+k}^{*} / P_{t}^{*}\right)\right]$. Accordingly, if we define $r_{k t} \equiv R_{k t}-E_{t}\left[\log \left(P_{t+k} / P_{t}\right)\right]$ and $r_{k t}^{*} \equiv R_{k t}^{*}-E_{t}\left[\log \left(P_{t+k}^{*} / P_{t}^{*}\right)\right]$ as the domestic and foreign ex ante real rate, we have the result that

$$
r_{k t}=r_{k t}^{*}
$$

Thus, under ex ante relative PPP and UIRP, ex ante real interest rates are equalised internationally.

\section{INDEX NUMBERS AS MEANS}

Government agencies typically measure inflation by collecting data on individual prices and then combining those in the form of some index-number formula. This approach is deterministic as it involves no uncertainty, the result being that the inflation rate "is what it is" -- no more, no less. 
An alternative approach is to view inflation as a signal-extraction problem, so that the individual prices contain information on the underlying rate of inflation, but this information is contaminated with "noise". The problem then becomes how to combine the individual prices so that the effects of noise are minimised. The solution involves some form of averaging of the prices. Under certain conditions, these averages coincide with popular index-number formulae used in the conventional approach. Although they are familiar, these measures of inflation have very different foundations from those employed by government agencies. The foundations are statistical, so that uncertainty plays a prominent and explicit role. For example, not only do we obtain a point estimate of inflation, but also a standard error, so that confidence intervals for the underlying rate of inflation can be constructed. This is known as the stochastic approach to index numbers.

The stochastic approach has recently been rehabilitated by Clements and Izan (1987) and Selvanathan and Rao (1994). ${ }^{6}$ As this will be used later in the paper to measure the world interest rate, we now set out the elements of this approach to illustrate the principles involved. For convenience, the measurement of inflation will be used here.

\section{The Basic Idea}

Let there be $n$ consumer goods with prices in period $t, P_{i t}, \ldots, P_{n t}$, and let $p_{i t}=\left(P_{i t} / P_{i, t-1}\right)$ be the $i^{\text {th }}$ price for this period in terms of last period's value. Note that $p_{i t}=1+g_{i t}$, with $g_{i t}=\left(P_{i t}-P_{i, t-1}\right) / P_{i, t-1}$ the growth rate in the $i^{\text {th }}$ price. Consider the following statistical model for the evolution of $p_{i t}$ :

$$
p_{i t}=\gamma_{t}+\varepsilon_{i t}
$$

where $\gamma_{t}$ is an unknown parameter and $\varepsilon_{i t}$ is an error term, such that

6 These authors provide references to previous literature on the subject. See Diewert (1995) for a critical review of the methodology. Other recent contributions to this area include Crompton (1996) and Selvanathan et al. (1997). 


$$
E\left[\varepsilon_{i t}\right]=0, \quad \operatorname{cov}\left[\varepsilon_{i t}, \varepsilon_{j t}\right]=\sigma_{t}^{2} \delta_{i j},
$$

where $\delta_{i j}$ is the Kronecker delta which takes the value 0 if $i \neq j$ and 1 if $i=j$. Model (3) holds for $i=1, \ldots, n$ prices, so the parameter $\gamma_{t}$ is interpreted as (one plus) the expected value of the growth rate common to all prices, i.e., $E\left(p_{i t}\right)=1+E\left(g_{i t}\right)=\gamma_{t}$. In other words, each price increases at the same rate except for a zero-mean random component. Accordingly, $\gamma_{t}$ could also be interpreted as the underlying rate of inflation.

The second member of equation (4) for $i \neq j$ states that the random components are uncorrelated over commodities. If we take $\gamma_{t}$ to the left-hand side of equation (3), we obtain $p_{i t}-\gamma_{t}=\varepsilon_{i t}$. The left-hand side of this equation is the growth in the $i^{\text {th }}$ price relative to the common growth rate, or the growth in the relative price of good $i$. Accordingly, the error term $\varepsilon_{i t}$ is the $i^{\text {th }}$ relative price change.

Next, consider the $n$ price changes $p_{i t}, \ldots, p_{n t}$. Under the assumptions in equation (4), the average of these $n$ price changes provide the best linear unbiased estimator (BLUE) of the rate of inflation, $\gamma_{t}$, in equation (3):

$$
\hat{\gamma}_{t}=\frac{1}{n} \sum_{i=1}^{n} p_{i t}
$$

The sampling variance of $\hat{\gamma}_{t}$ is

$$
\operatorname{var} \hat{\gamma}_{t}=\frac{1}{n} \sigma_{t}^{2}
$$

where $\sigma_{t}^{2}$ can be estimated unbiasedly by

$$
\hat{\sigma}_{t}^{2}=\frac{1}{n-1} \sum_{i=1}^{n}\left(p_{i t}-\hat{\gamma}_{t}\right)^{2}
$$


This expression is a measure of the variability in relative prices in that, when relative prices are unchanged, $p_{i t}=\hat{\gamma}_{t}(i=1, \ldots, n)$ and $\hat{\sigma}_{t}^{2}=0$; and when there is greater change in relative prices, $\hat{\sigma}_{t}^{2}$ increases.

The above perspective on the measurement of inflation illustrates the intuitive result that when there is more dispersion in relative prices, it is more difficult to obtain a precise estimate of the underlying rate of inflation. The sampling variance expression in (5) increases with relative price variability, and thus provides a natural formalisation of intuition.

\section{The Weighted Case}

The preceding approach can be improved upon by attributing more weight to those commodities which are more important in the consumer's budget. Let $q_{i, t-1}$ be the quantity demanded of good $i$ in period $t-1$, so that $p_{i, t-1} q_{i, t-1}$ is the expenditure on $i$ and $M_{t-1}=\sum_{i=1}^{n} p_{i, t-1} q_{i, t-1}$ is the total expenditure on all goods. Consequently, $w_{i, t-1}=\left(p_{i, t-1} q_{i, t-1}\right) / M_{t-1}$ is the share of total expenditure devoted to $i$, or the budget share of good $i$.

We replace (4) with

$$
E\left[\varepsilon_{i t}\right]=0, \quad \operatorname{cov}\left[\varepsilon_{i t}, \varepsilon_{j t}\right]=\frac{\lambda_{t}^{2}}{w_{i, t-1}} \delta_{i j}
$$

where $\lambda_{t}^{2}$ is a constant with respect to commodities. Thus, the variance of the relative price of $i$ is $\lambda_{t}^{2} / w_{i, t-1}$ and is inversely proportional to $w_{i, t-1}$. This means that the variability of a relative price falls as the commodity becomes more important in the consumer's budget. Clements and Izan (1987) justify this assumption on the basis that as a commodity becomes more important in the overall economy, there is less scope for its relative price to change.

Equation (6) means that generalised least squares (LS) is appropriate, which we shall 
implement in the form of weighted LS. We multiply both sides of (3) by $\sqrt{w_{i, t-1}}$ to give

$$
y_{i t}=\gamma_{t} x_{i, t-1}+u_{i t}
$$

where $y_{i t}=p_{i t} \sqrt{w_{i, t-1}}, x_{i, t-1}=\sqrt{w_{i, t-1}}$ and $u_{i t}=\varepsilon_{i t} \sqrt{w_{i, t-1}}$. It follows from (6) that

$$
\operatorname{cov}\left[u_{i t}, u_{j t}\right]=w_{i, t-1} \operatorname{cov}\left[\varepsilon_{i t}, \varepsilon_{j t}\right]=\lambda_{t}^{2} \delta_{i j}
$$

so that $\operatorname{var}\left[u_{i t}\right]=\lambda_{t}^{2}$, which is common for all commodities. Under the stated assumptions, we can thus apply LS to (7) to obtain the BLUE of $\gamma_{i}$ :

$$
\hat{\gamma}_{t}=\frac{\sum_{i=1}^{n} y_{i t} x_{i, t-1}}{\sum_{i=1}^{n} x_{i, t-1}^{2}}=\sum_{i=1}^{n} w_{i, t-1} p_{i t}
$$

where the second step follows from $\sum_{i=1}^{n} x_{i, t-1}^{2}=\sum_{i=1}^{n} w_{i, t-1}=1$. Equation (8) is a Laspeyres price index. The variance of $\hat{\gamma}_{t}$ is given by

$$
\operatorname{var} \hat{\gamma}_{t}=\frac{\lambda_{t}^{2}}{\sum_{i=1}^{n} x_{i, t-1}^{2}}=\frac{\lambda_{t}^{2}}{\sum_{i=1}^{n} w_{i, t-1}}=\lambda_{t}^{2}
$$

An unbiased estimate of $\lambda_{t}^{2}$ is given by

$$
\hat{\lambda}_{t}^{2}=\frac{1}{n-1} \sum_{i=1}^{n}\left(y_{i t}-\hat{\gamma}_{t} x_{i, t-1}\right)^{2}=\frac{1}{n-1} \sum_{i=1}^{n} w_{i, t-1}\left(p_{i t}-\hat{\gamma}_{t}\right)^{2}
$$

which we write as

$$
\operatorname{var} \hat{\gamma}_{t}=\frac{\Pi_{t}}{n-1}
$$


where $\Pi_{t}=\sum_{i=1}^{n} w_{i, t-1}\left(p_{i t}-\hat{\gamma}_{t}\right)^{2}$ is a weighted variance of relative price changes. ${ }^{7}$ This demonstrates that the variance of the price index $\hat{\gamma}_{t}$ is proportional to the degree of relative price variability across commodities. Consequently, the same basic result emerges, but in a weighted form.

\section{Systematic Changes in Relative Prices}

In the previous sub-sections, relative price changes are all assumed to be zero on average, i.e., the error term in equation (3), which represents the $i^{\text {th }}$ relative price change, has zero expectation. Following Clements and Izan (1987), we now extend our analysis to allow for systematic changes in relative prices.

We redefine $p_{i t}$ as the sum of the common trend in all prices, $\gamma_{t}$, a commodityspecific component, $\beta_{i}$, and a zero-mean random component, $\zeta_{i t}$ :

$$
p_{i t}=\gamma_{t}+\beta_{i}+\zeta_{i t}, \quad i=1, \ldots, n ; \quad t=1, \ldots, T
$$

where $T$ is the number of time periods. As before, $\gamma_{t}$ is the underlying rate of inflation. The parameter $\beta_{i}=E\left(p_{i t}-\gamma_{t}\right)$ is the expected change in the $i^{\text {th }}$ relative price. We assume that $\zeta_{i t}$ is independent over commodities and time and that its variance is inversely proportional to the corresponding budget-share:

$$
\operatorname{cov}\left[\zeta_{i t}, \zeta_{j s}\right]=\frac{\eta_{t}^{2}}{w_{i, t-1}} \delta_{i j}
$$

where $\eta_{t}^{2}$ is a constant with respect to commodities.

Since any increase in $\gamma_{t}$ for each $t$ by any number $k$ and a corresponding decrease in

7 This variance is closely related to the Divisia variance of prices (Theil, 1975/1976). 
$\beta_{i}$ for each $i$ by the same $k$ would not affect the right-hand side of (9), we need to impose a normalisation in order to identify the model. Clements and Izan (1987) set a budget-shareweighted average of the $\beta_{i}$ 's to zero:

$$
\sum_{i=1}^{n} w_{i, t-1} \beta_{i}=0
$$

Although there are an infinite number of normalisations, equation (10) has the attraction of permitting a simple, intuitive interpretation, viz. a budget-share-weighted-average of the relative price changes is zero.

We proceed as before and multiply both sides of (9) by $\sqrt{w_{i, t-1}}$ to obtain

$$
y_{i t}=\gamma_{t} x_{i t}+\beta_{i} x_{i t}+\zeta_{i t}^{\prime}
$$

where $\zeta_{i t}^{\prime}=\zeta_{i t} \sqrt{w_{i, t-1}}$. The LS estimators of (11), constrained by (10), are

$$
\hat{\gamma}_{t}=\sum_{i=1}^{n} w_{i, t-1} p_{i t}, \quad \hat{\beta}_{i}=\sum_{t=1}^{T} \phi_{t}\left(p_{i t}-\hat{\gamma}_{t}\right) .
$$

where $\phi_{t}=\left(1 / \eta_{t}^{2}\right) / \sum_{s=1}^{T}\left(1 / \eta_{s}^{2}\right)$. It is apparent that $\hat{\gamma}_{t}$ is the Laspeyres index, as before, while the estimator of the systematic component of the change in the relative price, $\hat{\beta}_{i}$, is a weighted average of the relative price changes $\left(p_{i t}-\hat{\gamma}_{t}\right)$ over all $T$ periods. The weights $\phi_{t}$ are inversely proportional to $\eta_{t}^{2}$, which, in turn, is proportional to the error variance in period $t$. This means that less weight is accorded to those observations with a higher variance. ${ }^{8}$

The variances of the estimators in (12) are

8 See Clements and Izan (1987) for details of the derivation of equation (12). 


$$
\operatorname{var} \hat{\gamma}_{t}=\eta_{t}^{2}, \quad \operatorname{var} \hat{\beta}_{i}=\frac{1}{\sum_{t=1}^{T}\left(1 / \eta_{t}^{2}\right)}\left(\frac{1}{w_{i, t-1}}-1\right)
$$

Here, we see that the variance of $\hat{\gamma}_{t}$ increases with $\eta_{t}^{2}$, which, in turn, rises with relative price variability. Therefore, we once again find that the variance of the estimator of overall price index is higher the larger the relative price movements. The variance of $\hat{\beta}_{i}$ is proportional to the difference between $1 / w_{i, t-1}$ and a constant term, which means that this variance increases as $w_{i, t-1}$ falls. ${ }^{9}$

\section{APPLICATION TO INTEREST RATES}

Recall that in model (9) we defined the price relative $p_{i t}$ as the sum of the common trend in all prices, $\gamma_{t}$, a commodity-specific component, $\beta_{i}$, and a zero-mean random component, $\zeta_{i t}$. Consider a similar model for real interest rates whereby each country's rate is the sum of the common component in all countries' real interest rates, a country-specific component and a zero-mean random component. Accordingly, we replace the commodity subscript $(i)$ in equation (9) with a country subscript $c(c=1, \ldots, C$ countries) and the price relative $p$ with the real interest rate $r$ :

$$
r_{c t}=\gamma_{t}+\beta_{c}+\zeta_{c t}
$$

If we reparameterise $\beta_{c}$ as $\mu+\alpha_{c}$, equation (14) then becomes

$$
r_{c t}=\gamma_{t}+\mu+\alpha_{c}+\zeta_{c t}
$$

As before, the parameters of model (15) are not identified. Consider the following normalisations:

9 See Clements and Izan (1987) for details of the derivation of equation (13). 


$$
\sum_{c=1}^{C} \alpha_{c}=0, \quad \sum_{t=1}^{T} \gamma_{t}=0 .
$$

This is an alternative to the normalisation in equation (10). The interpretation of model (15) is as follows. Since $r$ represents the change in a bond price, it is completely analogous to the price relative $p$, which is defined as $1+g$, with $g$ the rate of growth of the nominal price in question. The parameters $\mu+\gamma_{t}$ are the common components in all interest rates in the world, which is analogous to the overall rate of inflation in the case of prices. The parameter $\alpha_{c}$ is the country effect, which, as countries now play the role of commodities, is analogous to the relative price change before. This country effect tells us whether the interest rate in a particular country deviates from the world rate.

To proceed further, consider a variable $x_{c t}(c=1, \ldots, C ; t=1, \ldots, T)$ and let $x_{* t}=(1 / C) \sum_{c=1}^{C} x_{c t}$ be the average over the $c$ subscript and $x_{*}=(1 / T) \sum_{t=1}^{T} x_{* t}$ be the average of $x_{c t}$ over both subscripts. Thus, if we average (15) over $c=1, \ldots, C$, we obtain $r_{\bullet t}=\gamma_{t}+\mu+\zeta_{\bullet t}$, which follows from the first member of normalisation (16). Next, we average the above over $t=1, \ldots, T$, so that $r_{. .}=\mu$, which follows from the second member of (16) and the assumption $E\left(\zeta_{i t}\right)=0$. This means that $\mu$ is interpreted as the average real interest rate across all countries and time periods. In this sense, $\mu$ is the "world" interest rate.

Gagnon and Unferth (1995) implement model (15) as a dummy variable regression. The parameter $\gamma_{t}$ is estimated as the coefficient of a dummy variable that takes the value "1" in period $t$ and " 0 " in other periods, the parameter $\mu$ is the regression constant and $\alpha_{c}$ is estimated as the coefficient of a dummy variable that takes the value " 1 " for country $c$ and " 0 " for other countries. ${ }^{10}$ Clearly, Gagnon and Unferth's estimates can be reinterpreted in terms of stochastic index numbers. Gagnon and Unferth's data consist of annual real interest

10 Another perspective of Gagnon and Unferth's approach is that of a panel regression, whereby data are pooled over countries and time. The panel regression approach has two advantages over pure time-series regressions. It reduces the amount of time-series data required, but still provides sufficient data for powerful tests; moreover, it increases the volatility in the data by exploiting cross-sectional variation (see Frankel and Rose, 1995 and Hakkio, 1984). 
rates for Belgium, Britain, Canada, Denmark, Germany, Holland, Japan, Switzerland and the US, for the period September 1977 to December 1993.11 Thus, $C=9$ countries and $T=16$ periods when annual data are used. The authors define the real interest rate $r$ as the nominal interest rate observed in the last month of period $t-1$ minus the percentage change in the consumer price index from $t-1$ to $t$; accordingly, $r$ is an ex post real interest rate. Their results for annual data are given in the left-hand panel of Table 1, while Figure 1 shows the estimated country effects, $\alpha_{c}$, and the world real interest rate in year $t, \mu+\gamma_{t}$, together with its 95 percent confidence interval. ${ }^{12}$ The right-hand panel of Table 1 will be discussed later. We see from the left-hand panel that the country effects for all countries except Britain and Canada are significant. This suggests that there are significant departures of domestic interest rates from the world rate. Thus, these results imply a rejection of the hypothesis of strict RIRE.

Panel II of Figure 1 indicates that the real rate for the world varies substantially over time and the width of the 95 percent confidence interval averages 1.3 percent. Interestingly, the "cycles" in the world rate appear to coincide with the effects of economic policies of US presidents, as shown in Figure 2. For instance, the rate is not significantly different from zero in the earlier part of the sample period during the Carter Administration, when inflation and unemployment were high. Subsequently, the large budget deficits of the 1980's, together with disinflation, saw a tremendous surge in world interest rates in real terms. Figure 2 also gives the evolution of the Misery Index (which is the sum of the unemployment and inflation rates) for the US. ${ }^{13}$ As can be seen, the world rate is negatively correlated with the misery index (with a correlation coefficient of -0.53 ). This relationship suggests that world interest rates may be affected by US economic policies and that the treatment of the country effect $\alpha_{c}$

11 These countries are identified by the OECD as having relatively open and unrestricted financial markets (see OECD, 1990).

12 The parameter $\mu$ is the overall average real rate and $\gamma_{t}$ is the deviation at time $t$ from this average. The standard errors underlying the confidence interval are calculated as the square roots of $\left(\right.$ var $\left.\mu+v a r \gamma_{1}\right)$ as $\operatorname{cov}\left(\mu, \gamma_{t}\right)=0$.

13 The Misery Index is presented in Figure 2 as a deviation from its mean of 12.5 percent per annum. This index is obtained from The Economist, 15 June 1996, p. 72. 
for the US in model (15) as a constant is perhaps not the best way of proceeding.

Table 1

Estimates of the World Interest Rate Model for Nine OECD Countries:

Annual Data, 1978-1993

(Standard errors in parentheses)

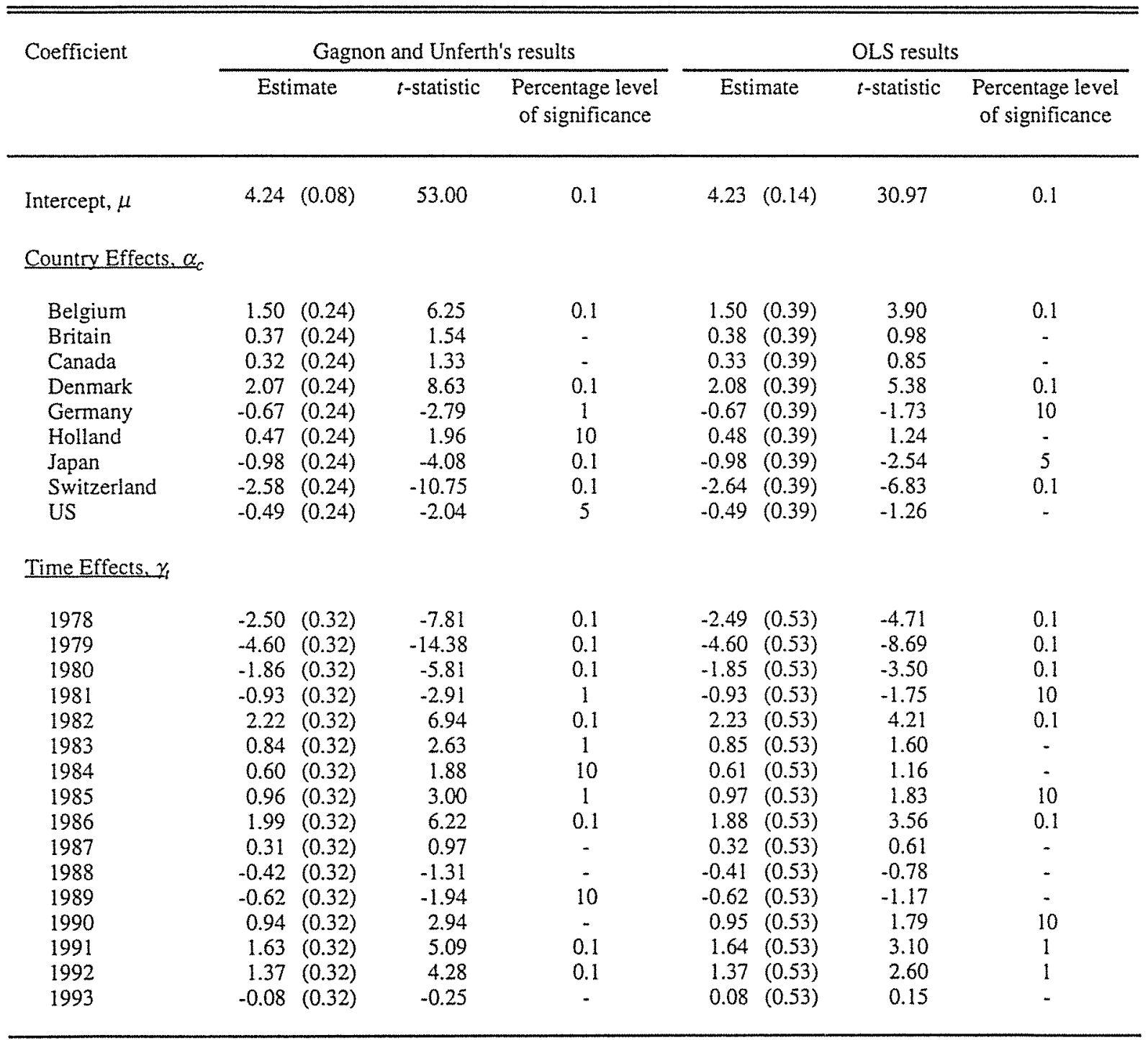

Notes: 1. The coefficient estimates and standard enors are to be divided by 100 .

2. The level of significance shows the probability of incorrectly rejecting the null hypothesis that the coefficient equals zero. Where "-" is indicated, this probability is more than 10 percent. 
Figure 1

Gagnon and Unferth's Estimates of the World Interest Rate Model:

Annual Data, 1978-1993

\section{Country Effects}

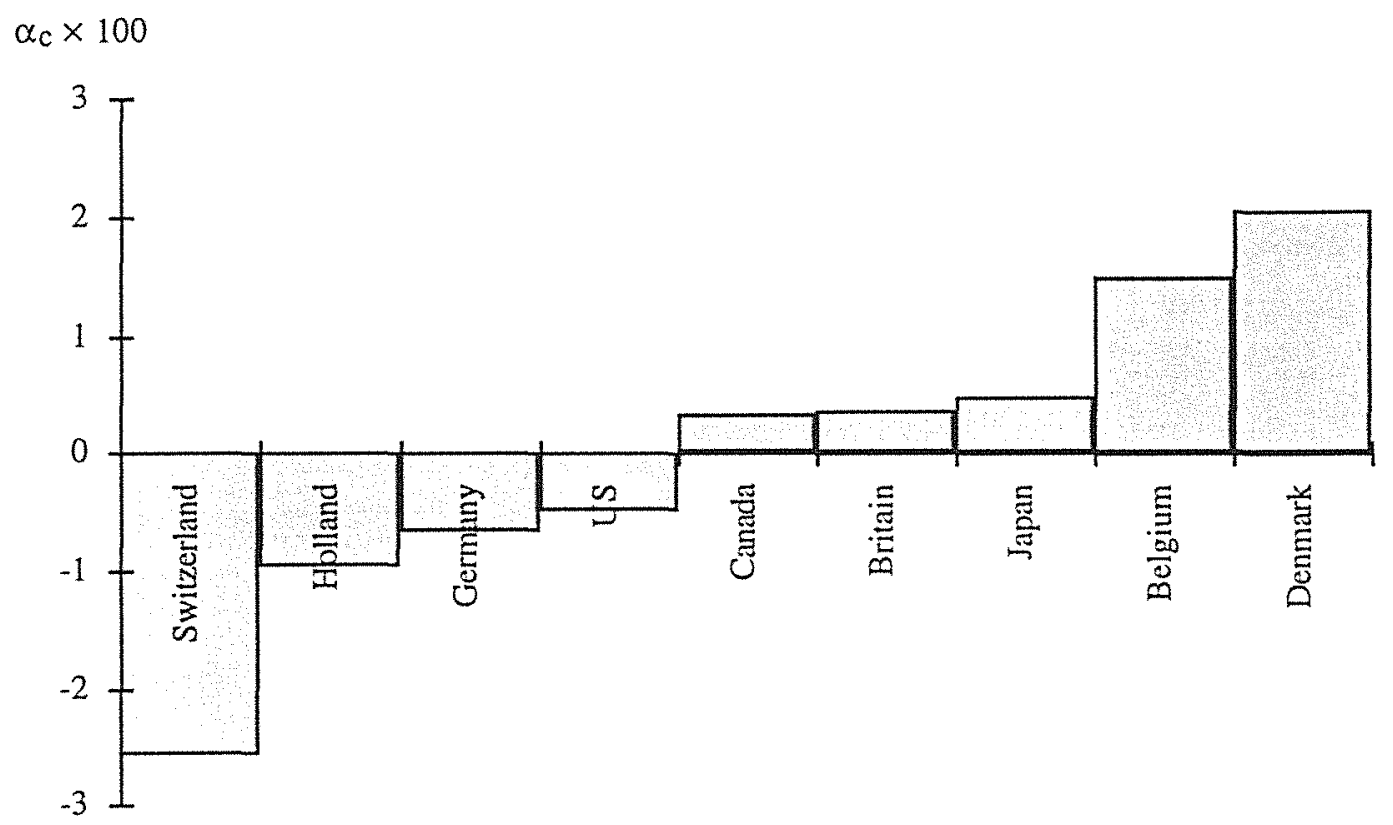

II. World Real Interest Rate and 95 Percent Confidence Interval

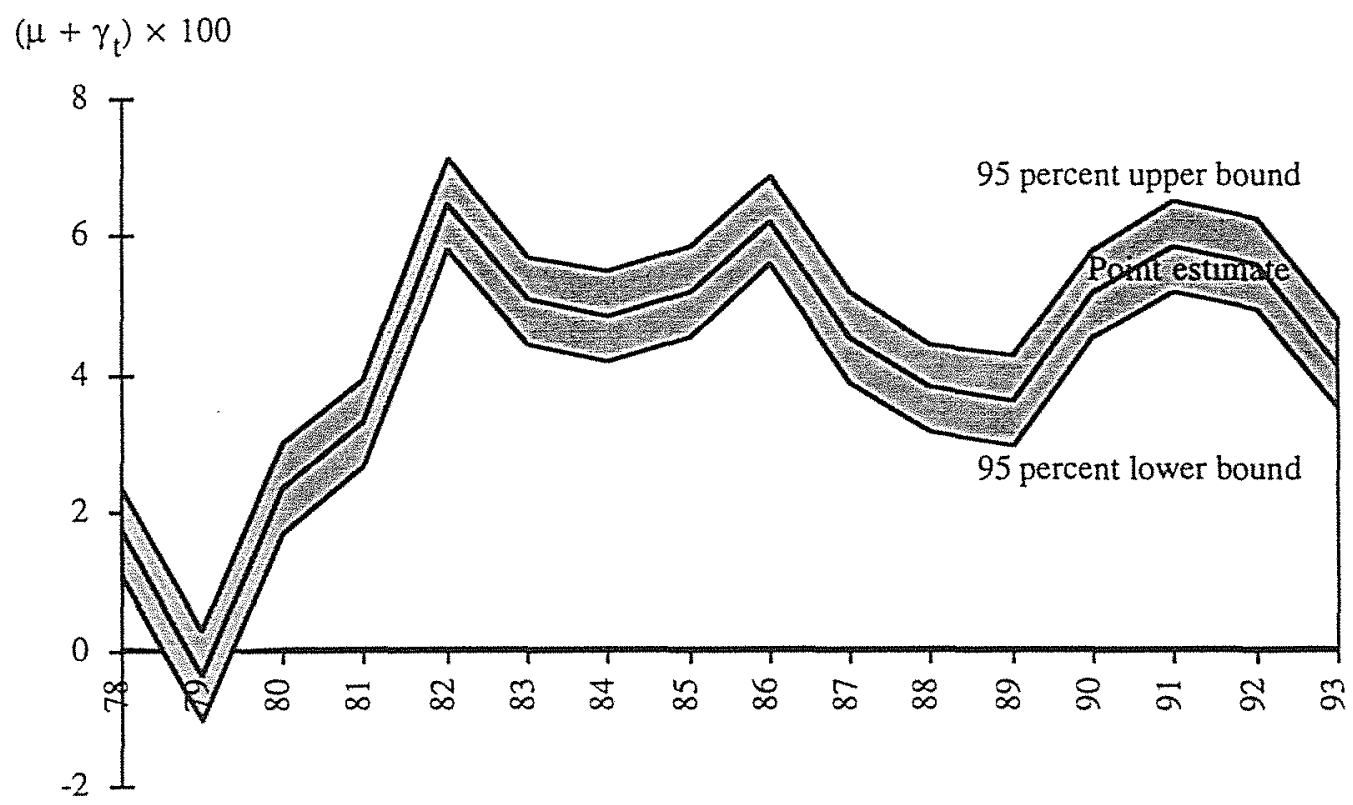


Figure 2

Comparison of US Economic Performance and World Real Interest Rates

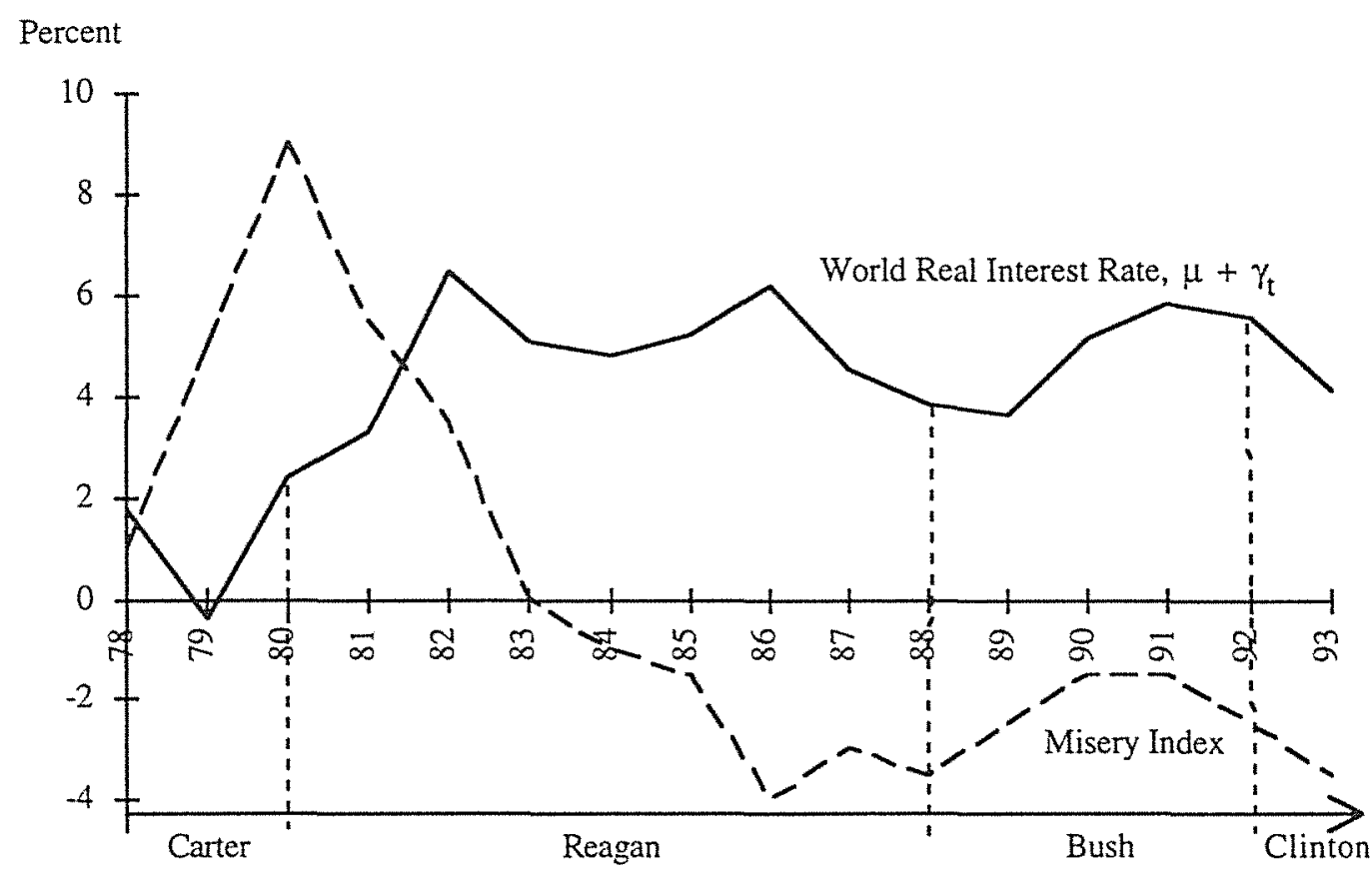

Gagnon and Unferth (1995) estimate their model by multi-variate LS, with the covariance matrix of the residuals restricted to be scalar. This procedure yields the same coefficient estimates as ordinary least squares (OLS); however the standard errors are computed differently. ${ }^{14}$ As there is no compelling reason to employ multi-variate LS, we reestimate by OLS using the same data for comparison purposes. We write equation (15) as a dummy variable regression:

$$
r_{c t}=\mu+\sum_{s=1}^{T} \gamma_{s} d_{c t s}+\sum_{d=1}^{C} \alpha_{d} z_{c t d}+\zeta_{c t}
$$

where $d_{c t s}=1$ if $t=s, 0$ otherwise; and $z_{c t d}=1$ if $c=d, 0$ otherwise. Using constraint (16) in the form $\alpha_{C}=-\sum_{c=1}^{C-1} \alpha_{c}, \gamma_{T}=-\sum_{t=1}^{T-1} \gamma_{t}$ in the above, we obtain

14 We are grateful to Joseph Gagnon for clarifying these issues, as well as supplying the interest rate and inflation data used in this paper. 


$$
r_{c t}=\mu+\sum_{s=1}^{T-1} \gamma_{s} d_{c t s}-\left(\sum_{s=1}^{T-1} \gamma_{s}\right) d_{c t T}+\sum_{d=1}^{C-1} \alpha_{d} z_{c t d}-\left(\sum_{d=1}^{C-1} \alpha_{d}\right) z_{c t C}+\zeta_{c t}
$$

or

$$
r_{c t}=\mu+\sum_{s=1}^{T-1} \gamma_{s} d_{c t s}^{\prime}+\sum_{d=1}^{C-1} \alpha_{d} z_{c t d}^{\prime}+\zeta_{c t}
$$

where $d_{c t s}^{\prime}=d_{c t s}-d_{c t T} ;$ and $z_{c t d}^{\prime}=z_{c t d}-z_{c t C}$

We use Gagnon and Unferth's data to estimate (17) by OLS and the results are contained in the right-hand panel of Table 1. Note that the estimates of the coefficients are virtually identical (as expected), while the standard errors increase so that the country and time effects are less significant. Now we find that the country effects for Holland and the US, in addition to Britain and Canada, are insignificant. However, Gagnon and Unferth's rejection of the strict hypothesis of RIRE still holds, as the $\alpha_{c}$ 's for Belgium, Denmark, Japan and Switzerland are significant.

\section{A WEIGHTED EXTENSION}

The significance of the country effects in Gagnon and Unferth's results imply a rejection of the hypothesis of a common real interest rate for the world. It could, however, be that their result is an artefact of their model (17), whereby equal importance is assigned to each country's influence on the world interest rate. In applying unweighted least squares to determine the world real interest rate, the same weight is given to interest rates in the US as, say, those of Denmark. Intuitively, we would expect the US, which on average makes up 50 percent of total GDP and contributes 30 percent of the total trade of our sample countries, to exert more influence on world interest rates than Denmark, which makes up 1 percent of GDP and 2 percent of total trade. Therefore, in this section we explore an alternative 
approach whereby countries exert differing influences on the world real interest rate, depending on their overall economic influence and integration with the rest of the world. This leads to a weighted world interest rate model which can be regarded as an application of (weighted) stochastic index-number methodology, as discussed above.

To estimate (17) by weighted LS, it is appropriate to weight the observations for country $c$ by the square root of some measure of the relative size of that country. The idea is that there is likely to be more variability in the interest rates in smaller countries, just as there is likely to be more variability in the relative price of less important commodities, as discussed in Clements and Izan (1987). Of course, giving less weight to smaller countries in this context can be justified directly without any appeal to the variability of interest rates. Let $w_{c, t-1}$ be a weight for country $c$ (the definition of this weight will be specified subsequently). We then multiply both sides of equation (17) by $\sqrt{w_{c, t-1}}$ to yield

$$
y_{c t}=\gamma_{t} x_{c t}+\mu x_{c t}+\alpha_{c} x_{c t}+\zeta_{c t}^{\prime}
$$

where $y_{c t}=r_{c t} \sqrt{w_{c, t-1}}, \quad x_{c t}=\sqrt{w_{c, t-1}}$ and $\zeta_{c t}^{\prime}=\zeta_{c t} \sqrt{w_{c, t-1}}$. The corresponding normalisations are

$$
\sum_{c=1}^{C} \alpha_{c} x_{c t}=0, \quad \quad \sum_{t=1}^{T} \gamma_{t} x_{c t}=0
$$

The LS estimators of (18), constrained by (19), are the analog of (12). Similarly, their sampling variances are the analog of (13) so that the variance of the estimated time component $\hat{\gamma}_{t}$ increases with real interest rate volatility, while the variance of the country component $\alpha_{c}$ increases as the country "size" falls.

We employ two different sets of weights: (i) the share of each country's total trade 
(exports plus imports) in total world trade; and (ii) the share in world GDP. ${ }^{15}$ The trade weighting scheme is used as it measures the degree of integration of the country in question with the world economy, while the GDP weights represent economic influence in terms of the contribution to world income. ${ }^{16}$ Our sample countries are Britain, Canada, Denmark, Germany, Japan, Holland and the US. ${ }^{17}$ As Belgium and Switzerland are now omitted, we re-estimate the unweighted model (15) for the seven OECD countries. A comparison of Table 2 with the right-hand panel of Table 1 reveals that the country effects are again significant for Denmark, Germany and Japan, with Britain, Canada, Holland and the US remaining insignificant.

We now apply the weighted model (18) to the data for the seven countries. The results for both GDP and trade weights are presented in Table 3. The country effects are now significant for Germany, Japan and the US, where GDP weights are used, and significant for Denmark, Germany, Japan and the US when trade weights are applied. It is also interesting to note that the time effects are mostly insignificant for the latter half of the sample for both sets of weights; this same pattern occurs previously. The estimates of the average real rate for the world are quite stable at a little over 4 percent per annum, whether or not weighting is used. A comparison of the Table 3 results with those in Table 2 reveals that there is only one major effect of employing country weights -- the country effect for the US becomes significant. However, the conclusion from this section must be that weighting countries does not seem to appreciably affect the tests of RIRE.

15 GDP and trade data are obtained from the International Financial Statistics of the International Monetary Fund.

16 The two sets of weights reveal some interesting patterns and contrasts. Not surprisingly, we find that the three major economies of US, Germany and Japan have the highest GDP and trade weights. However, while Japan is second richest in terms of GDP, its trade is less than that of Germany. Also of note is that there is more cross-country dispersion in the GDP shares than in the trade shares. The GDP share for the US increased during the first half of the 1980's, but has since fallen, while the opposite is true for Germany. Japan's share of world GDP has increased since the mid-1980's. Similarly, the US share of total world trade increased during the 1980's, while German trade fell. Japan's trade share increased in the early 1980's, but has remained constant since.

17 We are unable to include the full set of countries used by Gagnon and Unferth (1995) as the data for Belgium and Switzerland are incomplete. 
Table 2

Estimates of the World Interest Rate Model for Seven OECD Countries:

Annual Data, 1978-1993

(Standard errors in parentheses)

\begin{tabular}{|c|c|c|c|c|}
\hline \multirow{2}{*}{$\begin{array}{l}\text { Coefficient } \\
\text { Intercept, } \mu\end{array}$} & \multicolumn{2}{|c|}{ Estimate } & \multirow{2}{*}{$\frac{t \text {-statistic }}{26.44}$} & \multirow{2}{*}{$\begin{array}{c}\begin{array}{c}\text { Percentage level } \\
\text { of significance }\end{array} \\
0.1\end{array}$} \\
\hline & 4.39 & $(0.17)$ & & \\
\hline \multicolumn{5}{|c|}{ Country Effects, $\alpha_{c}$} \\
\hline Britain & 0.22 & $(0.41)$ & 0.53 & - \\
\hline Canada & 0.17 & $(0.41)$ & 0.41 & - \\
\hline Denmark & 1.92 & $(0.41)$ & 4.71 & 0.1 \\
\hline Germany & -0.83 & $(0.41)$ & -2.04 & 5 \\
\hline Holland & 0.32 & $(0.41)$ & 0.77 & - \\
\hline Japan & -1.14 & $(0.41)$ & -2.80 & 1 \\
\hline US & -0.65 & $(0.41)$ & -1.59 & - \\
\hline \multicolumn{5}{|c|}{ Time Effects $y_{t}$} \\
\hline 1978 & -3.06 & $(0.64)$ & -4.76 & 0.1 \\
\hline 1979 & -4.78 & $(0.64)$ & -7.43 & 0.1 \\
\hline 1980 & -2.27 & $(0.64)$ & -3.53 & 0.1 \\
\hline 1981 & -0.78 & $(0.64)$ & -1.21 & - \\
\hline 1982 & 2.50 & $(0.64)$ & 3.89 & 0.1 \\
\hline 1983 & 1.14 & $(0.64)$ & 1.78 & 10 \\
\hline 1984 & 0.82 & $(0.64)$ & 1.28 & - \\
\hline 1985 & 1.11 & $(0.64)$ & 1.72 & 10 \\
\hline 1986 & 1.87 & $(0.64)$ & 2.91 & 1 \\
\hline 1987 & 0.31 & $(0.64)$ & 0.49 & - \\
\hline 1988 & -0.45 & $(0.64)$ & -0.70 & - \\
\hline 1989 & -0.24 & $(0.64)$ & -0.37 & - \\
\hline 1990 & 0.96 & $(0.64)$ & 1.49 & - \\
\hline 1991 & 1.69 & $(0.64)$ & 2.63 & 1 \\
\hline 1992 & 1.18 & $(0.64)$ & 1.83 & 10 \\
\hline 1993 & 0.00 & $(0.64)$ & 0.00 & - \\
\hline
\end{tabular}

See notes to Table 1. 
Table 3

Estimates of the Weighted World Interest Rate Model for Seven OECD Countries:

Annual Data, 1978-1993

(Standard errors in parentheses)

\begin{tabular}{|c|c|c|c|c|c|c|}
\hline \multirow[t]{2}{*}{ Coefficient } & \multicolumn{3}{|c|}{ Weighted by GDP } & \multicolumn{3}{|c|}{ Weighted by Trade } \\
\hline & Estimate & $t$-statistic & $\begin{array}{l}\text { \% level of } \\
\text { significance }\end{array}$ & Estimate & t-statistic & $\begin{array}{l}\text { \% level of } \\
\text { significance }\end{array}$ \\
\hline Intercept, $\mu$ & $4.43(0.28)$ & 15.82 & 0.1 & $4.41 \quad(0.22)$ & 20.08 & 0.1 \\
\hline \multicolumn{7}{|c|}{ Country Effects, $\alpha_{c}$} \\
\hline Britain & $0.12(0.52)$ & 0.22 & - & $0.18 \quad(0.44)$ & 0.41 & - \\
\hline Canada & $0.08 \quad(0.62)$ & 0.12 & - & $0.13(0.50)$ & 0.27 & - \\
\hline Denmark & $2.01 \quad(1.23)$ & 1.64 & - & $1.98(0.94)$ & 2.11 & 5 \\
\hline Germany & $-0.79(0.30)$ & -2.61 & 5 & $0.74(0.31)$ & 2.37 & 5 \\
\hline Holland & $0.41 \quad(0.83)$ & 0.49 & - & $0.33(0.50)$ & 0.66 & - \\
\hline Japan & $-1.16(0.38)$ & -3.06 & 1 & $-1.16(0.39)$ & -2.99 & 1 \\
\hline US & $-0.66(0.33)$ & -1.99 & 5 & $-0.65(0.33)$ & -2.00 & 5 \\
\hline \multicolumn{7}{|c|}{ Time Effects, $y$} \\
\hline 1978 & $-4.31 \quad(0.56)$ & -7.74 & 0.1 & $-3.75(0.61)$ & -6.16 & 0.1 \\
\hline 1979 & $-5.54(0.56)$ & -9.95 & 0.1 & $-5.14(0.61)$ & -8.46 & 0.1 \\
\hline 1980 & $-2.85(0.56)$ & -5.12 & 0.1 & $-2.40 \quad(0.61)$ & -3.95 & 0.1 \\
\hline 1981 & $1.35(0.56)$ & 2.43 & 5 & $0.27(0.61)$ & 0.44 & - \\
\hline 1982 & $4.34(0.56)$ & 7.80 & 0.1 & $3.46(0.61)$ & 5.69 & 0.1 \\
\hline 1983 & $1.78 \quad(0.56)$ & 3.20 & 1 & $1.19(0.61)$ & 1.96 & 10 \\
\hline 1984 & $1.93(0.56)$ & 3.46 & 0.1 & $1.36(0.61)$ & 2.24 & 5 \\
\hline 1985 & $1.85(0.56)$ & 3.32 & 0.1 & $1.34(0.61)$ & 2.20 & 5 \\
\hline 1986 & $3.04(0.56)$ & 5.46 & 0.1 & $2.65(0.61)$ & 4.36 & 0.1 \\
\hline 1987 & $-0.82(0.56)$ & -1.47 & - & $-0.16(0.61)$ & -0.26 & - \\
\hline 1988 & $-0.26(0.56)$ & -0.46 & - & $-0.49(0.61)$ & -0.81 & - \\
\hline 1989 & $0.12(0.56)$ & 0.22 & - & $0.06 \quad(0.61)$ & 0.10 & - \\
\hline 1990 & $-0.58(0.56)$ & -1.04 & - & $0.18 \quad(0.61)$ & 0.30 & - \\
\hline 1991 & $1.35(0.56)$ & 2.42 & 5 & $1.50(0.61)$ & 2.46 & 5 \\
\hline 1992 & $-0.13(0.56)$ & -0.23 & - & $0.64(0.61)$ & 1.05 & - \\
\hline 1993 & $-1.26(0.56)$ & -2.26 & 5 & $-0.70 \quad(0.61)$ & -1.16 & - \\
\hline
\end{tabular}

See notes to Table 1.

\section{FURTHER EXTENSIONS}

So far, we have tested for RIRE using annual data. We now re-estimate model (18) using quarterly data to test for the short-term validity of RIRE. In doing so, we find that country effects are similar to those using annual data, i.e., $\alpha_{c}$ for Germany, Japan and the US are significant when GDP weights are used, while those for Denmark, Germany, Japan and 
the US are significant when trade weighting is applied. The significance of the time effects are similar to the annual estimates. ${ }^{18}$

To determine whether capital market intervention affects interest rate equalisation, we extend the sample to include countries that have more restricted capital markets, namely, Austria, France, Italy, Norway and Sweden (OECD, 1990). Surprisingly, we find that all five "restricted" countries generally do not have significant country effects, except for France when trade weights are used. ${ }^{19}$ The country effects for the "unrestricted" economies are similar to earlier estimates, but are now more significant.

We also analyse the effects of using the WPI as an alternative to the CPI to derive real interest rates. Dutton (1993) argues that because the prices of non-traded goods are poorly arbitraged, real interest rates should be defined in terms of the prices of traded goods alone for the purposes of international comparisons. Since the WPI is made up of mainly traded goods, we re-estimate using annual real interest rates defined in terms of the WPI for the seven OECD countries with free capital markets. ${ }^{20}$ The results are presented in Table 4 . In this table, there are three sets of results: (i) unweighted; (ii) weighted by GDP; and (iii) weighted by trade. Comparing the unweighted results with those obtained with the CPI (Table 2), we see that using the WPI has the effect of making all the country coefficients insignificant, whereas in Table 2, three of the seven country coefficients are significant. This means that RIRE now holds, contradicting Gagnon and Unferth's (1985) findings with the CPI. Similar results of insignificant country effects emerge in the unweighted WPI case when we use quarterly data for (i) the seven countries; and (ii) the 12 countries (the additional five have restricted capital markets). ${ }^{21}$

18 These estimates are available on request. Results for the unweighted model with quarterly data show significant country effects for Denmark, Japan and the US, compared to Denmark, Germany and Japan for annual data.

19 Detailed results are available on request.

20 The WPI data are also provided by Joseph Gagnon.

21 Detailed results are available on request. 
Table 4

Estimates of the Weighted World Interest Rate Model for Seven OECD Countries:

Annual Data Dellated by WPI, 1978 to 1993

(Standard errors in parentheses)

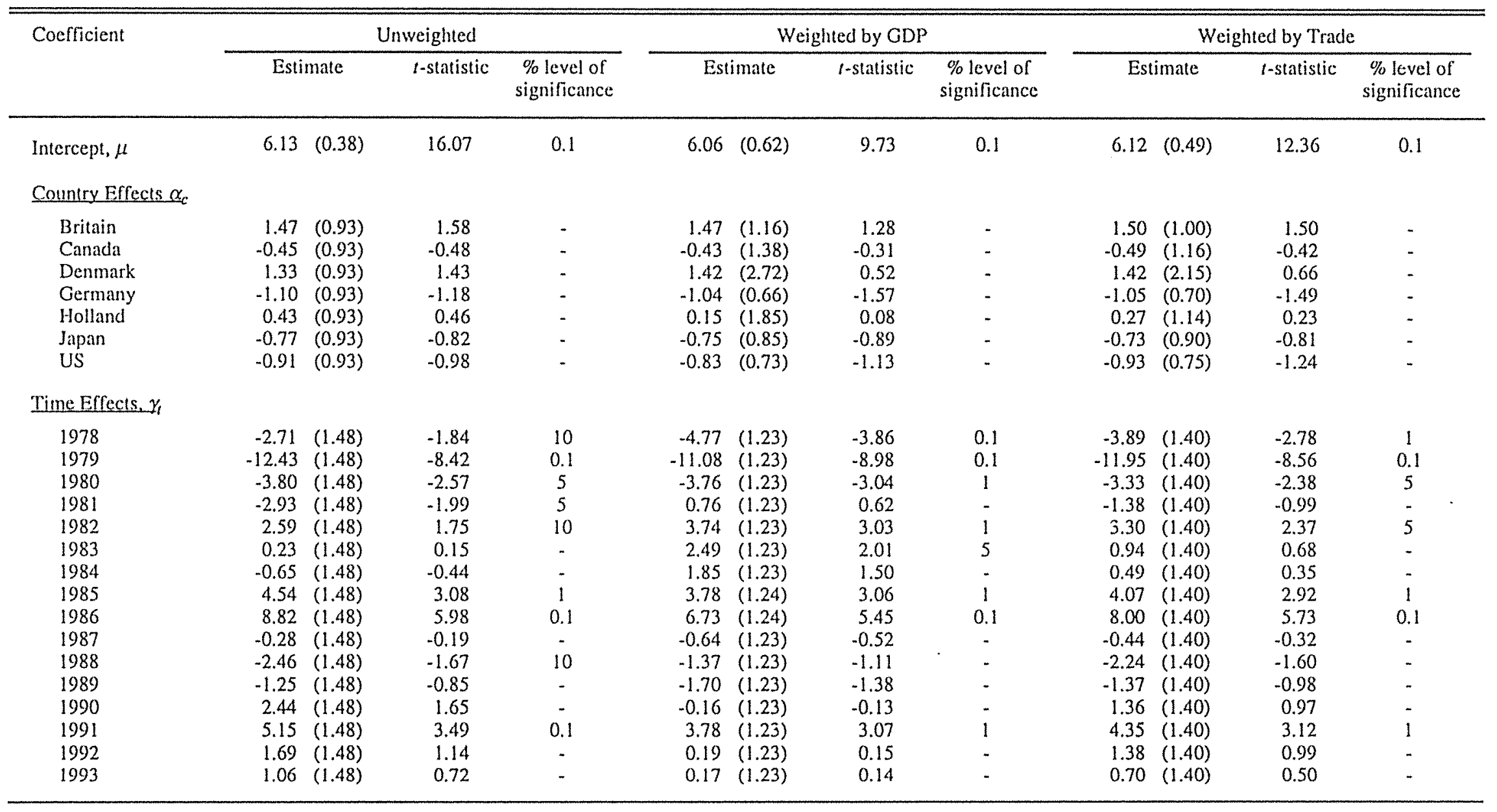

See notes to Table 1. 
Next, we compare the GDP-weighted results, given in the middle panel of Table 4 , with those in the left-hand panel of Table 3. Since GDP weights are used in both cases, this comparison involves only the WPI (Table 4) against the CPI (Table 3). The country effects are now insignificant in all cases, while previously, three were significant. We thus conclude that here also the WPI results are more supportive of RIRE. ${ }^{22}$ Finally, regarding the trade weights, we compare the results in the far right-hand panel of Table 4 with those in the right panel of Table 3. As can be seen, the effect of moving from the CPI to the WPI is to reduce the number of significant country coefficients from four to none. ${ }^{23}$

The main finding thus far is as follows. When real rates are defined in terms of the WPI, which excludes many goods that do not enter into international trade, none of the country effects are significant. In other words, there is now more support for the hypothesis that real rates are equalised internationally. This result seems to hold on both a quarterly and annual basis. Consider now a more formal comparison between the CPI and the WPI. Let the "true" rate of inflation be a weighted average of the growth rates of the CPI and WPI, $\pi^{C P I}$ and $\pi^{W P I}$ :

$$
\pi=\lambda\left(\pi^{C P I}\right)+(1-\lambda)\left(\pi^{W P I}\right)
$$

where $\lambda$ is the weight given to the CPI. The real interest rate in terms of the true deflator (or the "true" real rate) is then $r=i-\pi$, or $r=i-\left[\lambda\left(\pi^{C P I}\right)+(1-\lambda)\left(\pi^{W P I}\right)\right]$. Alternatively, we could write it as $r=r^{W P I}-\lambda\left(\pi^{C P I}-\pi^{W P I}\right)$, where $r^{W P I}=i-\pi^{W P I}$ is the real rate defined in terms of the WPI. It then follows that if we use the true real rate, equation (15) becomes

$$
r_{c t}^{W P I}=\gamma_{t}+\mu+\alpha_{c}+\lambda\left(\pi_{c t}^{C P I}-\pi_{c t}^{W P I}\right)+\zeta_{c t}
$$

22 We also use GDP weights and the WPI with (i) quarterly data; and (ii) the 12 countries. For (i), the findings are similar with those using annual data, with all country effects being insignificant. For (ii), again all country effects are insignificant.

23 We also use trade weights and the WPI with (i) quarterly data; and (ii) the 12 countries. As with the GDP weights, we find that all country effects are insignificant in both cases. 
This equation shows that the unknown weight $\lambda$ can be estimated as a coefficient. Equation (20) also reveals that $\lambda$ has the additional interpretation as the response of the WPI real rate to relative prices, $\partial r^{W P I} / \partial\left(\pi^{C P I}-\pi^{W P I}\right)$, which is reminiscent of the Tobin-Mundell effect. $^{24}$

Estimates of equation (20) using annual data are presented in Table 5. Interestingly, we find that the results are very similar to those in Table 2, where CPI real interest rates are used. The WPI real rate appears highly responsive to relative price changes, with $\lambda$ insignificantly different from 1 . This indicates that the true real rate is very similar to the CPI real rate. Similar results to those using quarterly CPI-deflated interest rates are obtained when we re-estimate equation (20) with data for (i) the seven countries; and (ii) the 12 countries including those with restricted capital markets. For these cases, the estimated CPI weight $\lambda$ remains high at 0.92 and 0.93 , respectively. 25

We thus conclude that the true rate of inflation is largely based on CPI prices, where "true" is interpreted in terms of the appropriate deflator for the real interest rate. It appears that while the WPI real rate is equalised internationally, neither the CPI real rate nor the true real rate is equalised. Another interpretation of our results is that the goods and services that enter into the calculation of the CPI are very different from the mainly tradeable goods that are used in deriving the WPI.

24 See Mundell (1963) and Tobin (1965).

25 Detailed results are available on request. 
Table 5

Estimates of the True Real Interest Rate with Relative Price Changes for Seven OECD Countries:

Annual Data, 1978-1993

(Standard errors in parentheses)

\begin{tabular}{|c|c|c|c|c|}
\hline \multirow{2}{*}{$\begin{array}{l}\text { Coefficient } \\
\text { Intercept, } \mu\end{array}$} & \multicolumn{2}{|c|}{ Estimate } & \multirow{2}{*}{$\frac{t \text {-statistic }}{22.79}$} & \multirow{2}{*}{$\begin{array}{c}\begin{array}{c}\text { Percentage leve } \\
\text { of significance }\end{array} \\
0.1\end{array}$} \\
\hline & 4.33 & $(0.19)$ & & \\
\hline \multicolumn{5}{|l|}{ Country Effects, $\alpha_{c}$} \\
\hline Britain & 0.18 & $(0.41)$ & 0.43 & - \\
\hline Canada & 0.19 & $(0.41)$ & 0.46 & - \\
\hline Denmark & 1.94 & $(0.41)$ & 4.76 & 0.1 \\
\hline Germany & -0.82 & $(0.41)$ & -2.01 & 5 \\
\hline Holland & 0.31 & $(0.41)$ & 0.77 & - \\
\hline Japan & -1.15 & $(0.41)$ & -2.83 & 1 \\
\hline US & -0.64 & $(0.41)$ & -1.57 & - \\
\hline \multicolumn{5}{|l|}{ Time Effects. $y_{t}$} \\
\hline 1978 & -3.07 & $(0.65)$ & -4.76 & 0.1 \\
\hline 1979 & -4.52 & $(0.76)$ & -5.94 & 0.1 \\
\hline 1980 & -2.22 & $(0.65)$ & -3.42 & 0.1 \\
\hline 1981 & -0.71 & $(0.66)$ & -1.08 & \\
\hline 1982 & 2.50 & $(0.65)$ & 3.87 & 0.1 \\
\hline 1983 & 1.18 & $(0.65)$ & 1.82 & 10 \\
\hline 1984 & 0.87 & $(0.65)$ & 1.34 & - \\
\hline 1985 & 0.99 & $(0.67)$ & 1.48 & - \\
\hline 1986 & 1.64 & $(0.74)$ & 2.21 & 5 \\
\hline 1987 & 0.33 & $(0.65)$ & 0.52 & - \\
\hline 1988 & -0.39 & $(0.65)$ & -0.60 & - \\
\hline 1989 & -0.20 & $(0.65)$ & -0.31 & - \\
\hline 1990 & 0.91 & $(0.65)$ & 1.39 & - \\
\hline 1991 & 1.57 & $(0.67)$ & 2.35 & 5 \\
\hline 1992 & 1.16 & $(0.65)$ & 1.79 & 10 \\
\hline 1993 & -0.02 & $(0.65)$ & -0.04 & - \\
\hline Relative Price Changes, $\lambda$ & 1.03 & $(0.05)$ & 19.56 & 0.1 \\
\hline
\end{tabular}

Note: See notes to Table 1.

\section{SUMMARY AND CONCLUSION}

The integration of world capital markets would tend to equalise the cost of borrowing funds, in real terms, across countries. Recent research has investigated the extent to which this in fact occurs, by examining departures of domestic interest rates from those prevailing in the world. While earlier research tests whether pairs of countries have the same interest rates, 
in a pioneering study Gagnon and Unferth (1995) introduce a methodology which applies to all major countries simultaneously. Their approach is to regress interest rates across countries and over time on dummy variables for each period and each country. Interest rates in a given country are then said to exhibit departures from the world rate if the coefficient of the dummy variable for that country is significant.

Another recent area of research is what is known as "stochastic index numbers" (Clements and Izan, 1987, Selvanathan and Rao, 1994). When applied to prices, the underlying rate of inflation is treated as an unknown parameter to be estimated from the individual price data. Each individual price contains noisy information on the underlying rate of inflation and the effect of the noise is minimised by employing some type of averaging of the individual prices. The attractiveness of this approach is that it leads to not only a point estimate of inflation, but also a standard error. This standard error increases with the degree of relative price variability, which agrees with the intuitive notion that, in some sense, inflation is less well-defined when there is substantial variation in relative prices.

In this paper, we combine these two areas of research. We show that Gagnon and Unferth's model can be interpreted as an application of the stochastic approach to index numbers. Additionally, we extend their approach by weighting countries to recognise their differing importance in the world economy, in terms of overall income and trade. It turns out, however, that weighting per se does not substantially affect the results. We also examine the argument that tests of RIRE are sensitive to the choice of the price index used to deflate nominal interest rates. In doing so, we deflate by the WPI, which comprises a high proportion of traded goods. In contrast to Gagnon and Unferth's CPI results, when the WPI is used, all the country effects are insignificant, so that we are unable to reject the hypothesis that WPI real rates are equalised internationally. We also find that the "true" real interest rate, defined as the nominal rate less a weighted average of changes in the CPI and WPI, is very similar to the CPI real rate and that this true rate is not equalised internationally. 


\section{REFERENCES}

Bilson, J. F. O. (1981). "The 'Speculative Efficiency' Hypothesis." Journal of Business 54: 435-51.

Clements, K. W. and H. Y. Izan (1987). "The Measurement of Inflation: A Stochastic Approach." Journal of Business and Economic Statistics 5: 339-50.

Click, R. W. (1996). "Contrarian MacParity." Economics Letters 53: 209-12.

Crompton, P. (1996). "A Reconsideration of the New Stochastic Approach to Index Numbers." Discussion Paper, No. 96.42, Department of Economics, The University of Western Australia.

Cumby, R. E. (1988). "Is It Risk? Explaining Deviations from Uncovered Interest Parity." Journal of Monetary Economics 22: 279-99.

(1996). "Forecasting Exchange Rates on the Hamburger Standard: What You See is What You Get with McParity." NBER Working Paper Series, No. 5675, National Bureau of Economic Research.

and F. S. Mishkin (1986). "The International Linkage of Real Interest Rates: The European-US Connection." Journal of International Money and Finance 5: 5-23.

and M. Obstfeld (1984). "International Interest Rate and Price Level Linkages Under Floating Exchange Rates: A Review of Recent Evidence." In J. F. O. Bilson and R. Marston (eds.), Exchange Rate Theory and Practice. Chicago: University of Chicago Press. Pp. 121-151.

Diewert, W. E. (1995). "On the Stochastic Approach to Index Numbers." Discussion Paper, No. 95-31, Department of Economics, University of British Columbia, Vancouver.

Domowitz, I. and C. Hakkio (1985). "Conditional Variance and the Risk Premium in the Foreign Exchange Market." Journal of International Economics 19: 47-66.

Dooley, M. and P. Isard (1980). "Capital Controls, Political Risk, and Deviations from Interest-Rate Parity." Journal of Political Economy 88: 370-84.

Dutton, M. M. (1993). "Real Interest Rate Parity: New Measures and Tests." Journal of International Money and Finance 12: 62-77.

Edison, H. J. and W. R. Melick (1995). "Alternative Approaches to Real Exchange Rates and Real Interest Rates: Three Up and Three Down." International Finance Discussion Papers, No. 518, Board of Governors of the Federal Reserve System.

and B. D. Pauls (1993). "A Re-assessment of the Relationship between Real Exchange Rates and Real Interest Rates: 1974-1990." Journal of Monetary Economics 31: 165-87.

Evans, M. D. D. and K. K. Lewis (1995). "Do Long-Term Swings in the Dollar Affect Estimates of the Risk Premium?" Review of Financial Studies 8: 709-42. 
Fama, E. F. (1984). "Forward and Spot Exchange Rates." Journal of Monetary Economics 14: $319-38$.

Frankel, J. A. (1982). "In Search of the Exchange Risk Premium: A Six Currency Test Assuming Mean-Variance Optimisation." Journal of International Money and Finance 1: $255-74$.

(1988). "Recent Estimates of Time-Variation in the Conditional Variance and in the Exchange Risk Premium." Journal of International Money and Finance 7: 11525.

and A. K. Rose (1995). "A Panel Project on Purchasing Power Parity: Mean Reversion within and between Countries." Journal of International Economics 40: 209-24.

Frenkel, J. A. and R. M. Levich (1975). "Covered Interest Arbitrage: Unexploited Profits?" Journal of Political Economy 83: 325-38.

and

(1977). "Transaction Costs and Interest Arbitrage: Tranquil versus Turbulent Periods." Journal of Political Economy 85: 1209-26.

Gagnon, J. E. and M. D. Unferth (1995). "Is There a Real World Interest Rate?" Journal of International Money and Finance 14: 845-55.

Hakkio, C. S. (1984). "A Re-Examination of Purchasing Power Parity: A Multi-Country and Multi-Period Study." Journal of International Economics 17: 265-77.

Hansen, L. P. and R. J. Hodrick (1983). "Risk Averse Speculation in the Forward Foreign Exchange Market: An Econometric Analysis of Linear Models." In J. A. Frenkel (ed.), Exchange Rates and International Macroeconomics. Chicago: University of Chicago Press. Pp. 113-42.

Hodrick, R. J. (1979). "Some Evidence on the Equality of Expected Real Interest Rates across Countries." Working Paper, No. 8-79-80, Graduate School of Industrial Administration, Carnegie-Mellon University.

and S. Srivastava (1984). "An Investigation of Risk and Return in Forward Foreign Exchange." Journal of International Money and Finance 3: 5-29.

Hsieh, D. A. (1984). "Tests of Rational Expectations and No Risk Premium in Forward Exchange Rates." Journal of International Economics 17: 173-84.

Lewis, K. (1995). "Puzzles in International Financial Markets." In G. Grossman and K Rogoff (eds.), Handbook of International Economics, Vol. 3. Amsterdam: NorthHolland.

Mark, N. C. (1985). "Some Evidence on the International Inequality of Real Interest Rates." Journal of International Money and Finance 4: 189-208.

Meese, R. A. and K. Rogoff (1988). "Was It Real? The Exchange Rate Interest Rate Relation, 1973-1984." Journal of Finance 43: 933-48. 
Mishkin, F. S. (1984). "Are Real Interest Rates Equal Across Countries: An Empirical Investigation of International Parity Conditions." Journal of Finance 39: 1345-57.

Mundell, R. A. (1963). "Inflation and Real Interest." Joumal of Political Economy 71: 28083.

Mussa, M. L. and M. Goldstein (1993). "The Integration of World Capital Markets." Changing Capital Markets: Implications for Monetary Policy. Proceedings of the Federal Reserve Bank of Kansas City Symposium, Jackson Hole. Pp. 245-313.

OECD (1990). Liberalisation of Capital Movements and Financial Services in the OECD Area, Organisation for Economic Co-operation and Development, Paris.

Oh, K.-Y. (1996). "Purchasing Power Parity and Unit Root Tests Using Panel Data." Journal of International Money and Finance 15: 405-18.

Ong, L. L. (1997). "Burgernomics: The Economics of the Big Mac Standard." Journal of International Money and Finance (forthcoming).

Orr, A., M. Edey and M. Kennedy (1995). "The Determinants of Real Long-Term Interest Rates: 17 Country Pooled-Time-Series Evidence." Working Paper, No. 155, Economics Department, Organisation for Economic Co-operation and Development, Paris.

Pakko, M. R. and P. S. Pollard (1996). "For Here or to Go? Purchasing Power Parity and the Big Mac." Federal Reserve Bank of St. Louis Review 78: 3-21.

Piggott, C. A. (1993). "International Interest Rate Convergence: A Survey of the Issues and Evidence." Federal Reserve Bank of New York Quarterly Review 18: 24-37.

Pope, P. F. and Peel, D. A. (1991). "Forward Foreign Exchange Rates and Risk Premia -- A Reappraisal." Journal of International Money and Finance 10: 443-56.

Popper, H. (1990). "International Capital Mobility: Direct Evidence from Long-Term Currency Swaps." International Finance Discussion Paper, No. 386, Board of Governors of the Federal Reserve System.

Rogoff, K. (1996). "The Purchasing Power Parity Puzzle." Journal of Economic Literature 34: $647-68$.

Selvanathan, E. A. and D. S. Prasada Rao (1994). Index Numbers: A Stochastic Approach. London: Macmillan.

Selvanathan, E. A., D. S. Prasada Rao and H. E. Doran (1997). "Estimation of General and Commodity-Specific Rates of Inflation Using Linear Time-Varying Constraints." Presented at the Australasian Economic Society Meeting, Melbourne.

The Economist, 15 June 1996.

Theil, H. (1975/76). Theory and Measurement of Consumer Demand. Two Volumes. Amsterdam: North-Holland Press. 
Tobin, J. (1965). "Money and Economic Growth." Econometrica 33: 671-84. 